\title{
Cost-effectiveness of volumetric alcohol taxation in Australia
}

\author{
Joshua M Byrnes, Linda J Cobiac, Christopher M Doran, Theo Vos and Anthony P Shakeshaft
}

Tr n 2008, Australians aged 15 years and over consumed, on average, the equivalent of $9.95 \mathrm{~L}$ of pure ethanol per person. ${ }^{l}$ To reduce the lifetime risk from alcohol-related harm, National Health and Medical Research Council (NHMRC) guidelines recommend consuming no more than two standard drinks per day for both sexes, and, to reduce the risk on a single occasion of drinking, consuming no more than four standard drinks for both sexes. ${ }^{2}$ In 2007 , $60.8 \%$ of the population drank at levels considered to pose low risk of harm in the short and long term, while $10.3 \%$ and $20.4 \%$ drank at levels considered risky in the short and long term, respectively. ${ }^{3}$ The social cost of alcohol consumption in the 2004-05 financial year was estimated at $\$ 15.3$ billion, second to the cost of tobacco and almost double the cost of illicit drugs (\$8.2 billion). ${ }^{4}$ Alcohol-related harm accounted for $3.2 \%$ of the total burden of disease and injury in Australia in 2003, equating to 3430 deaths and 85435 disability-adjusted life-years (DALYs). ${ }^{5}$

A strategy to reduce alcohol-related harm is to reduce the average consumption of alcohol across the population. ${ }^{6}$ Evidence suggests that increasing the price of alcohol (usually via taxation) reduces consumption: a meta-analysis of 112 studies, comprising 1003 estimates of price-elasticity (see glossary, Box 1), found a significant negative relationship between alcohol price increases and consumption. ${ }^{7}$

In Australia, the United States and United Kingdom, excise taxes vary according to

\section{Glossary}

Price-elasticity: The extent to which consumption changes in response to price changes.

Cross-price elasticity: The change in consumption per unit change in the price of other products

Income elasticity: The change in consumption per unit of change in income.

Consumer benefit: The difference between the value an individual places on a product and the price paid for the product.

Deadweight loss of taxation: The reduction in consumer benefit from taxation that increases the price and lowers consumption, less the taxation revenue collected.

\section{ABSTRACT}

Objective: To estimate the potential health benefits and cost savings of an alcohol tax rate that applies equally to all alcoholic beverages based on their alcohol content (volumetric tax) and to compare the cost savings with the cost of implementation.

Design and setting: Mathematical modelling of three scenarios of volumetric alcohol taxation for the population of Australia: (i) no change in deadweight loss, (ii) no change in tax revenue, and (iii) all alcoholic beverages taxed at the same rate as spirits.

Main outcome measures: Estimated change in alcohol consumption, tax revenue and health benefit.

Results: The estimated cost of changing to a volumetric tax rate is $\$ 18$ million. A volumetric tax that is deadweight loss-neutral would increase the cost of beer and wine and reduce the cost of spirits, resulting in an estimated annual increase in taxation revenue of $\$ 492$ million and a $2.77 \%$ reduction in annual consumption of pure alcohol. The estimated net health gain would be 21000 disability-adjusted life-years (DALYs), with potential cost offsets of $\$ 110$ million per annum. A tax revenue-neutral scenario would result in an $0.05 \%$ decrease in consumption, and a tax on all alcohol at a spirits rate would reduce consumption by $23.85 \%$ and increase revenue by $\$ 3094$ million. All volumetric tax scenarios would provide greater health benefits and cost savings to the health sector than the existing taxation system, based on current understandings of alcohol-related health effects.

Conclusions: An equalised volumetric tax that would reduce beer and wine consumption while increasing the consumption of spirits would need to be approached with caution. Further research is required to examine whether alcohol-related health effects vary by type of alcoholic beverage independent of the amount of alcohol consumed to provide a strong evidence platform for alcohol taxation policies.

MJA 2010; 192: 439-443

beverage type. ${ }^{8-10}$ In Australia, beer is taxed according to alcohol content above a $1.15 \%$ tax-free threshold, spirits are taxed at a higher rate, and wine is taxed as a percentage of the wholesale price. In contrast, a volumetric tax would apply the same rate of tax per litre of alcohol across all beverages. ${ }^{11}$ Increased taxes are generally passed on to consumers in the form of higher alcohol prices. This loss of consumer benefit (Box 1) may be partially offset by the redistribution of the additional taxation revenue as welfare and other government spending. However, the amount of tax collected and redistributed is likely to be substantially less than the loss in consumer benefit, a difference termed "deadweight loss" of taxation.

Our study aimed to estimate the public health benefits and costs of implementing a volumetric alcohol tax in Australia. We assessed three scenarios for a volumetric tax rate:

- A rate that maintains the current deadweight loss of taxation;

- A rate that maintains existing taxation revenue; and
- A rate equal to the existing rate applied to spirits.

\section{METHODS}

\section{Volumetric tax rate and data sources}

The volumetric tax rates for the deadweight loss-neutral and taxation revenue-neutral scenarios were calculated using the goal seek function in Microsoft Excel, version 4.5 (Microsoft Corporation, Seattle, Wash, USA).

The tax rates calculated for the three scenarios were:

- \$28.61 per litre of pure alcohol to maintain the current deadweight loss; this was calculated by varying the tax rate continuously until the deadweight loss equalled that of the current tax system;

- \$24.81 per litre of pure alcohol to maintain the current level of taxation revenue; and

- \$57.97 per litre of pure alcohol to be consistent with the current tax rate applied to spirits.

We obtained published estimates of price elasticity for beer, wine and spirits. ${ }^{12}$ As no 
estimates were available for ready-to-drink (RTD) alcoholic beverages, their price elasticity was assumed to equal that of straight spirits. The only significant cross-price elasticity (the extent to which consumption of one beverage changes in response to price changes of another beverage) was a negative relationship between the price of beer and the consumption of spirits (raising beer prices reduces an individual's budget to purchase spirits). ${ }^{11}$

\section{Intervention effect}

Uncertainty in the net effect on alcohol consumption of implementing a volumetric tax was assumed to be normally distributed, with a standard error plus or minus $20 \%$ of the point estimate. The change in alcohol consumption was reduced by $3 \%$ per annum, which is the estimated growth in gross domestic product in Australia ${ }^{13}$ multiplied by an income elasticity of 1 (Box 1 ), to account for real growth in income. ${ }^{12}$

\section{Cost estimates}

The cost to government of implementing a volumetric tax in Australia has been estimated at $\$ 18$ million. ${ }^{14}$ To take account of the uncertainty of this estimate, we assumed that the cost varied between $\$ 14.4$ million and $\$ 21.6$ million. Reduction in future health expenditure (cost offsets) from the prevention of future disease and future complications was calculated in this model using data from the Australian Burden of Disease study $^{5}$ and the Disease Costs and Impacts Studies. ${ }^{15}$ All costs were adjusted to the 2003 reference year using the consumer price index for health. ${ }^{16}$

\section{Measurement of health benefits}

A multistate life table model ${ }^{17}$ was used to measure the health benefits derived from implementing a volumetric tax in Australia. This model captured short-term and longterm consequences of reduced alcohol consumption using both disease and injury models. Diseases included ischaemic heart disease, ischaemic stroke, breast cancer, mouth and oropharyngeal cancer, oesophageal cancer, liver cancer, laryngeal cancer, hypertensive heart disease, cardiomyopathy, gallbladder and bile duct disease, pancreatitis, cirrhosis and alcohol use disorders. Injuries included road traffic accidents, falls, fires, burns and scalds, drowning, machinery accidents, suffocation and foreign bodies, suicide and self-inflicted injuries, and homicide and violence.

\section{Relative risks of alcohol-related diseases at different intake levels (with abstinence as the reference value) ${ }^{18}$}

\begin{tabular}{|c|c|c|c|c|}
\hline \multirow{2}{*}{$\begin{array}{l}\text { Disease and } \\
\text { data source }\end{array}$} & \multirow[b]{2}{*}{ Sex } & \multicolumn{3}{|c|}{ Intake level* } \\
\hline & & Low & Hazardous & Harmful \\
\hline \multirow[t]{2}{*}{ Ischaemic heart disease $^{19}$} & $M$ & $0.85(0.82-0.88)$ & $0.84(0.80-0.87)$ & $1.00(0.94-1.07)$ \\
\hline & $\mathrm{F}$ & $0.87(0.84-0.90)$ & $0.92(0.87-0.96)$ & $1.20(1.06-1.35)$ \\
\hline \multirow[t]{2}{*}{ Ischaemic stroke ${ }^{20 \dagger}$} & M & $1.02(0.84-1.21)$ & $1.44(1.15-1.79)$ & $1.84(1.02-3.04)$ \\
\hline & $\mathrm{F}$ & $0.62(0.50-0.77)$ & $0.77(0.52-1.09)$ & $1.47(0.41-3.77)$ \\
\hline \multirow[t]{2}{*}{ Breast cancer ${ }^{20}$} & $M$ & - & - & - \\
\hline & $\mathrm{F}$ & $1.14(1.09-1.20)$ & $1.41(1.32-1.50)$ & $1.59(1.43-1.78)$ \\
\hline \multirow{2}{*}{$\begin{array}{l}\text { Mouth and oropharynx } \\
\text { cancer }^{19}\end{array}$} & M & $1.58(1.35-1.87)$ & $2.95(1.92-4.63)$ & $5.41(1.78-16.53)$ \\
\hline & $\mathrm{F}$ & $1.32(1.11-1.63)$ & $2.01(1.44-2.85)$ & 3.89 (1.97-10.62) \\
\hline \multirow[t]{2}{*}{ Oesophageal cancer ${ }^{19}$} & M & $1.32(1.19-1.46)$ & $2.17(1.71-2.75)$ & $4.42(0.91-2.57)$ \\
\hline & $\mathrm{F}$ & $1.18(1.11-1.26)$ & $1.56(1.38-1.76)$ & $2.05(1.65-2.57)$ \\
\hline \multirow[t]{2}{*}{ Liver cancer ${ }^{19}$} & M & $1.13(1.07-1.20)$ & $1.39(1.21-1.60)$ & $1.79(1.23-2.57)$ \\
\hline & $\mathrm{F}$ & $1.07(1.04-1.11)$ & $1.22(1.13-1.31)$ & 1.49 (1.29-1.75) \\
\hline \multirow[t]{2}{*}{ Larynx cancer ${ }^{19}$} & M & $1.13(1.07-1.20)$ & $1.49(1.21-1.81)$ & $2.08(1.40-3.08)$ \\
\hline & $\mathrm{F}$ & $1.07(1.04-1.11)$ & $1.23(1.14-1.32)$ & $1.63(1.37-1.97)$ \\
\hline \multirow{2}{*}{$\begin{array}{l}\text { Hypertensive heart } \\
\text { disease }^{19}\end{array}$} & M & $1.26(1.20-1.32)$ & $1.97(1.76-2.23)$ & $4.03(2.93-5.53)$ \\
\hline & F & $1.14(1.11-1.18)$ & $1.45(1.35-1.55)$ & $2.45(2.15-2.84)$ \\
\hline \multirow[t]{2}{*}{ Cardiomyopathy ${ }^{5 \ddagger}$} & M & $1.00(1.00-1.00)$ & $1.43(1.33-1.54)$ & $2.24(1.93-2.55)$ \\
\hline & $\mathrm{F}$ & $1.00(1.00-1.00)$ & $1.87(1.65-2.09)$ & $3.49(2.86-4.11)$ \\
\hline \multirow{2}{*}{$\begin{array}{l}\text { Gallbladder and bile duct } \\
\text { disease }^{21}\end{array}$} & M & $0.82(0.76-0.90)$ & $0.68(0.55-0.84)$ & $0.50(0.33-0.75)$ \\
\hline & $\mathrm{F}$ & $0.82(0.76-0.90)$ & $0.68(0.55-0.84)$ & $0.50(0.33-0.75)$ \\
\hline \multirow[t]{2}{*}{ Pancreatitis $^{19}$} & M & $1.19(1.10-1.30)$ & $1.78(1.35-2.40)$ & $3.15(1.77-5.47)$ \\
\hline & $\mathrm{F}$ & $1.11(1.06-1.16)$ & $1.34(1.21-1.50)$ & $2.10(1.61-2.79)$ \\
\hline \multirow[t]{2}{*}{ Hepatic cirrhosis ${ }^{19}$} & M & $1.39(1.17-1.67)$ & $2.36(1.43-3.91)$ & $4.33(1.32-13.61)$ \\
\hline & $\mathrm{F}$ & $1.36(1.08-1.82)$ & $2.14(1.39-3.45)$ & $5.21(2.18-21.39)$ \\
\hline
\end{tabular}

$\mathrm{F}=$ female. $\mathrm{M}=$ male. ${ }^{*}$ Values are mean relative risk and $95 \% \mathrm{Cl}$ at average alcohol consumption for intake category versus abstinence.

† Weighted average of relative risks for ischaemic and haemorrhagic stroke (weighting based on incidence). $\ddagger$ Derived from population-attributable fraction of $0.10^{5}$ and prevalence of alcohol use, ${ }^{3}$ assuming linearly increasing risk with increasing consumption above low levels of alcohol use.

Epidemiological inputs to the disease models were taken from the Australian Burden of Disease study, including projected trends in incidence and case fatality. ${ }^{5}$ Trends were assumed to continue over the next 20 years, with disease rates remaining constant thereafter.

The average disability associated with each disease was taken from estimates of prevalence and severity-weighted years lived with disability for each disease. ${ }^{5}$ The relative risks for each disease and data sources are shown in Box 2. The change in relative risk of each disease was calculated from the change in alcohol consumption by assuming a linear increase (or decrease) in disease risk with increasing (or decreasing) alcohol consumption. This is a method of interpolating between the relative risks reported in the literature to capture the change in risk arising from a change in consumption.

The relationship between relative risk of mortality or disability from injury and alcohol consumption was assumed to be exponential. Exponential coefficients were estimated for each injury from direct estimates of the proportion of injuries attributed to alcohol ${ }^{5}$ and data on the prevalence of alcohol use in the Australian population. ${ }^{3}$ Total health gains are reported in disabilityadjusted life-years (DALYs) averted - a single measure that accounts for both increases in years of life as well as gains in health.

\section{Discount rate}

A base year of 2003 was selected, consistent with the Australian Burden of Disease study. A constant discount rate of 3\% was applied 


\section{Estimated changes in quantity of pure alcohol consumed and taxation revenue achieved by volumetric taxation}

\begin{tabular}{|c|c|c|c|c|}
\hline Scenario & Price* & $\begin{array}{c}\text { Pure } \\
\text { alcohol* }^{*}\end{array}$ & $\begin{array}{c}\text { Tax revenue } \\
(\$ \mathrm{M})^{\dagger}\end{array}$ & $\begin{array}{l}\text { Net deadweight } \\
\text { loss }(\$ M)^{\dagger}\end{array}$ \\
\hline \multicolumn{5}{|l|}{ Deadweight-loss neutral } \\
\hline Beer & $+10.7 \%$ & $-4.6 \%$ & +507 & +116 \\
\hline Wine & $+17.6 \%$ & $-6.5 \%$ & +600 & +93 \\
\hline Spirits - bottle & $-22.8 \%$ & $+13.6 \%$ & -526 & -205 \\
\hline Spirits - ready-to-drink & $-3.5 \%$ & $-2.5 \%$ & -88 & -4 \\
\hline Total & - & $-2.77 \%^{\ddagger}$ & +492 & 0 \\
\hline \multicolumn{5}{|l|}{ Taxation-revenue neutral } \\
\hline Beer & $+5.2 \%$ & $-2.3 \%$ & +255 & +53 \\
\hline Wine & $+12.8 \%$ & $-4.7 \%$ & +444 & +63 \\
\hline Spirits - bottle & $-25.8 \%$ & $+18.8 \%$ & -583 & -237 \\
\hline Spirits — ready-to-drink & $-5.9 \%$ & $+2.3 \%$ & -115 & -23 \\
\hline Total & - & $-0.05 \%^{\ddagger}$ & 0 & -144 \\
\hline \multicolumn{5}{|l|}{ Current spirits excise } \\
\hline Beer & $+53 \%$ & $-22.9 \%$ & +1936 & +865 \\
\hline Wine & $+55 \%$ & $-20.4 \%$ & +1568 & +449 \\
\hline Spirits - bottle & 0 & $-26.6 \%$ & -366 & +183 \\
\hline Spirits — ready-to-drink & $+15 \%$ & $-38.9 \%$ & -44 & +226 \\
\hline Total & - & $-23.85 \%^{\ddagger}$ & +3094 & 1723 \\
\hline
\end{tabular}

to both health benefits and costs accruing in the future.

\section{Uncertainty analysis}

Cost offsets were assumed to vary uniformly by $25 \%$. Uncertainty in each relative risk of disease was assumed to be normally distributed around the logarithm of the relative risk. Uncertainty was evaluated by Monte Carlo simulation (2000 iterations) using @RISK software (@RISK VBA Macro Language Risk Analysis and Simulation Add-In for Microsoft Excel Version 4.5 [Palisade Corporation, Newfield, NY, USA]). A 95\% uncertainty interval was calculated by taking the 2.5 and 97.5 percentiles of the distribution of results generated by the iterations of the simulation. This uncertainty interval can be interpreted as the range within which the true result lies with $95 \%$ certainty. The results estimated by the model were graphed on a cost-effectiveness plane to express the associated uncertainty range.

\section{RESULTS}

A volumetric tax rate with no change in current deadweight loss results is predicted to result in a $2.77 \%$ reduction in annual consumption of pure alcohol and an estimated annual increase in taxation revenue of $\$ 492$ million (Box 3). In this scenario, the price of spirits and RTD beverages decreased and the price of beer and wine increased. The increased consumption of spirits was more than offset by reduced consumption of beer and wine. A tax revenue-neutral scenario also increased the price of beer and wine and decreased the price of spirits and
RTD beverages, but resulted in only a marginal decrease $(0.05 \%)$ in overall alcohol consumption. A volumetric tax set equal to the current spirits tax rate provided a substantially greater reduction $(23.85 \%)$ in consumption of alcohol and an increase in taxation revenue of $\$ 3094$ million.

In the current spirits-excise scenario, although the price of spirits was unchanged, their consumption decreased. This result derived from the increase in the price of beer: the negative relationship between the price of beer and consumption of spirits, measured by the cross-price elasticity, means that spirit consumption falls as people's budget for alcohol is reduced by higher prices paid for beer.

The cost of changing the taxation system for alcohol is estimated at $\$ 18$ million, or an annualised equivalent of $\$ 0.58$ million. There is evidence that all three scenarios of volumetric taxation would reduce health costs and increase health gains compared with current policy. The net health gain associated with a deadweight loss-neutral tax change is estimated at 21000 DALYs averted, and the net cost as $-\$ 110$ million per annum (Box 4). The tax revenue-neutral scenario provides a much smaller health gain of 380 DALYs and net cost of $-\$ 1.4$ million. A volumetric tax rate equal to that of the current spirits excise provides the greatest health gain of 170000 DALYs and net cost of $-\$ 870$ million.

The cost-effectiveness plane for a deadweight loss-neutral volumetric tax is shown in Box 5. Each point represents one of the 2000 simulated results calculated to represent uncertainty around inputs to the model. The $x$ axis measures the DALYs averted by the intervention, and the $y$ axis measures the net cost of the intervention (a negative value on the $y$ axis indicates a cost saving). The graph shows that all estimates have a $y$ value less than 0 and an $x$ value greater than 0 , indicating that the intervention is cost-saving and associated with a health gain.

\section{DISCUSSION}

Our study aimed to estimate the public health benefits and costs of implementing a

\section{Disability-adjusted life-years (DALYs) averted, cost offsets and net cost of volumetric taxation}

\begin{tabular}{lcccc} 
Scenario (alcohol decrease*) & DALYs averted & Cost offsets (\$M) & Intervention cost (\$M) & Net cost (\$M) \\
\hline Deadweight-loss neutral (2.77\%) & $21000(12000$ to 31000$)$ & $-\$ 110(-\$ 210$ to $-\$ 36)$ & $\$ 0.58(\$ 0.47$ to $\$ 0.69)$ & $-\$ 110(-\$ 210$ to $-\$ 36)$ \\
Tax revenue-neutral (0.05\%) & $380(220$ to 570$)$ & $-\$ 2.0(-\$ 3.7$ to $-\$ 0.69)$ & $\$ 0.58(\$ 0.47$ to $\$ 0.69)$ & $-\$ 1.4(-\$ 3.20$ to $-\$ 0.11)$ \\
Current spirits excise $(23.85 \%)$ & $170000(99000$ to 250000$)$ & $-\$ 870(-\$ 1600$ to $-\$ 300)$ & $\$ 0.58(\$ 0.47$ to $\$ 0.69)$ & $-\$ 870(-\$ 1600$ to $-\$ 290)$ \\
\hline * Predicted decrease in alcohol consumption. & & &
\end{tabular}


volumetric alcohol tax in Australia. However, a number of caveats must be noted. First, we modelled the reduction in average alcohol consumption arising from an equalised volumetric tax. It is possible that consumption would not be reduced evenly across the population, as responses to price changes might vary between subgroups. If the response to price changes was less (or greater) for high-risk drinkers than for lowor moderate-risk drinkers, the estimated health benefits of the predicted fall in consumption might be over- (or under-) estimated. Further, long-term risky drinkers might be more (or less) price-sensitive than short-term risky drinkers. Thus, the nature of health benefits accruing from reduced consumption might vary.

Second, we used estimates of price elasticity for beer, wine and spirits that date from $1994,{ }^{11}$ and were unable to obtain an estimate for ready-to-drink (pre-mixed) beverages, so assumed it was equal to that of spirits. In addition, our model assumed that the type of alcoholic beverage consumed does not affect drinking-risk behaviour, but rather that the pure alcohol content is solely responsible. Our failure to account for the alcohol density of beverages and the rate at which people become intoxicated could have resulted in an overestimate of the potential health gains of an equalised volumetric tax.

Furthermore, both the negative and positive health effects of alcohol consumption were modelled, but the positive effects are debated. ${ }^{22}$ Thus, the health effects reported here might underestimate the full health impact of reduced alcohol consumption.

Finally, our analysis was conducted from a health-sector perspective, and included hospital and medical costs averted from reduced alcohol consumption but not other significant social costs averted, such as crime.

Evidence from the WHO-CHOICE study ${ }^{14}$ suggests that the most efficient public health response to the burden of alcohol misuse depends on the prevalence of alcohol use. Taxation represented the most costeffective response in countries such as Australia with moderate or high levels of drinking. Our results indicate that the method of alcohol taxation is important in efficiently reducing the harm caused by alcohol use. An equalised volumetric alcohol tax is a cost-effective policy that would deliver significant health gains compared with existing taxation in Australia, which applies inconsistent rates per litre of pure alcohol.

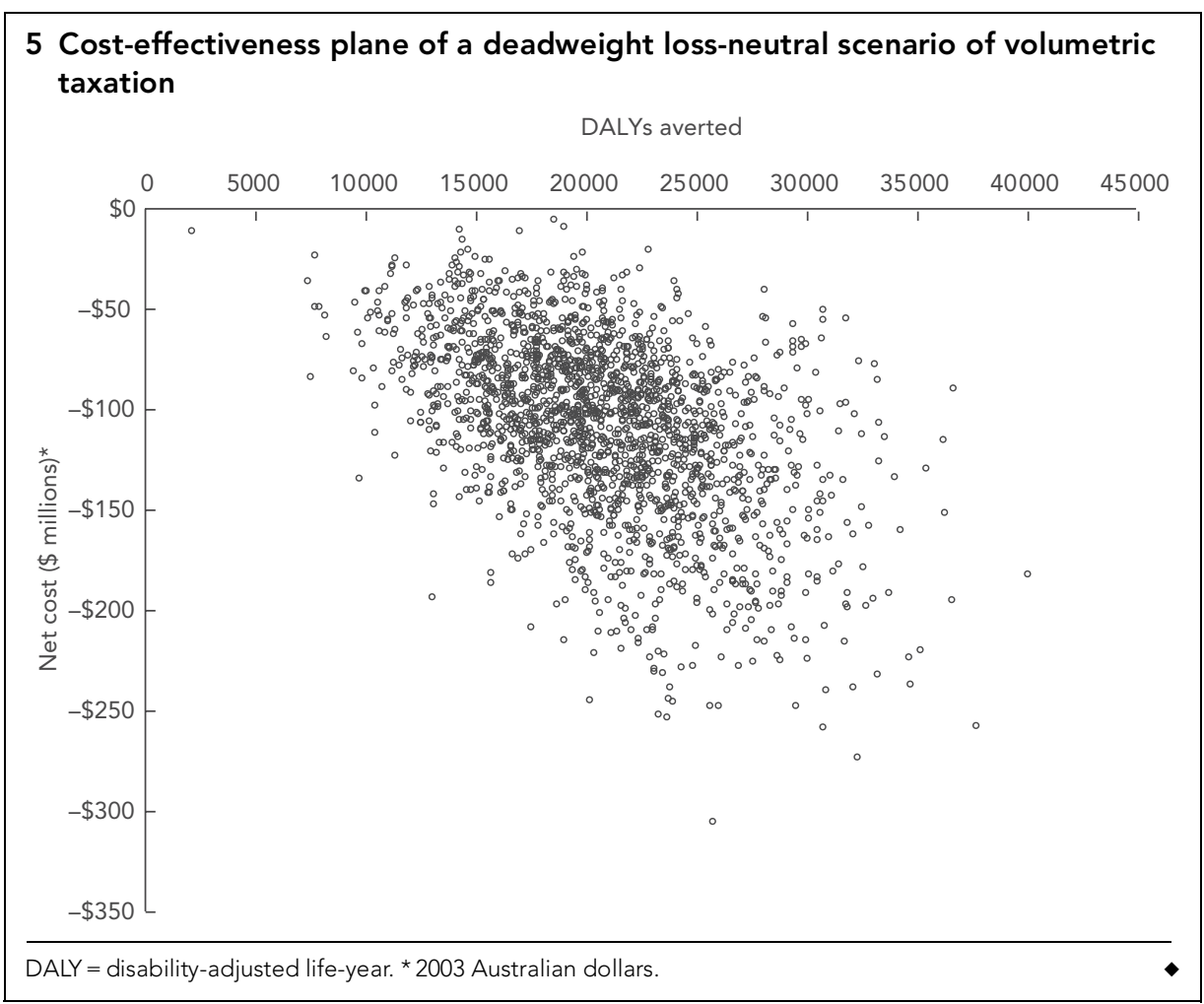

6 Further criteria to consider before implementing volumetric alcohol taxation

Equity

- The burden of intervention (amount paid) will be proportional to the amount of alcohol consumed.

- Low-income drinkers will be more affected (tax-to-income ratio is greater).

Acceptability to stakeholders

- The intervention is low-cost and will generate significant offsets.

- Alcohol lobby groups (or companies) are likely to oppose the decision (as they may lose revenue), which may influence government policy.

- The political scenario and perceived acceptance by voters will be other determinants for acceptability among politicians.

- A section of the health-conscious population may accept volumetric taxation, whereas alcohol consumers may object to paying more for alcohol.

Feasibility and sustainability

- Systems are already in place to implement and monitor the intervention.

- Once implemented, it would need minimal resources to ensure sustainability.

Potential for side effects

- There are no negative side effects related to health.

- There may be positive side effects, such as productivity gains arising from reduced alcohol consumption, and decreases in road crashes, violence and crime.

However, in prioritising interventions, we need to combine technical approaches, such as economic evaluation, with approaches that facilitate due process. ${ }^{23}$ Other criteria often considered in evaluating health interventions include the capacity of the intervention to reduce inequity, acceptability to stakeholders, feasibility, sustainability, and potential for other consequences. Aspects of these criteria to con- sider before implementing volumetric taxation are shown in Box 6. These issues might have positive and negative effects on its acceptability. For example, a volumetric tax might be considered equitable in that the more individuals drink, the more they are taxed, but this approach might also be opposed by alcohol lobby groups, especially those in sectors whose sales are predicted to decline. 
Systems are already in place to implement and monitor volumetric alcohol taxation and, once implemented, minimal resources would be needed to ensure its sustainability. The recent change in tax rates applied to pre-mixed alcoholic drinks highlights the Australian government's motivation to adopt evidence-based policy. ${ }^{24,25}$ However, the vocal opposition from the alcohol industry demonstrates the political hurdles to such reform. In particular, a volumetric taxation system has the potential to create winners and losers within the alcohol industry although spirits producers would potentially welcome the system, the beer and wine sectors are likely to oppose a relative tax increase on their products.

The potential for different alcoholic beverage types to have different impacts necessitates caution in interpreting our results. Based on current understanding of the health effects of alcohol, we recommend a volumetric tax. However, research that focuses on specific beverage types is required. A tiered approach to alcohol taxation that respects evidence on beveragespecific health effects might prove more beneficial. Furthermore, analyses with a broader scope incorporating the significant social costs of alcohol consumption would enhance the evidence base. Nevertheless, the political hurdles to implementing evidence-based policy in public health remain the largest barrier to be overcome.

\section{ACKNOWLEDGEMENTS}

Our research was funded by an Alcohol Education and Rehabilitation Foundation grant.

\section{COMPETING INTERESTS}

The funding body had no role in study design, data collection, analysis and interpretation or writing of this article.

\section{AUTHOR DETAILS}

Joshua M Byrnes, BComm, MEconStud, MHealthEcon, Senior Researcher ${ }^{1}$

Linda J Cobiac, BEng(Hons), MEngSc,

MPhil(Maths), Research Officer ${ }^{2}$

Christopher M Doran, BEcon(Hons), PhD,

Associate Professor ${ }^{1}$

Theo Vos, MSc, PhD, Director and Professor ${ }^{2}$

Anthony P Shakeshaft, MA(Psych), PhD,

Associate Professor ${ }^{1}$

1 National Drug and Alcohol Research Centre, University of New South Wales, Sydney, NSW.

2 Centre for Burden of Disease and CostEffectiveness, School of Population Health, University of Queensland, Brisbane, QLD. Correspondence:

z3229463@student.unsw.edu.au

\section{REFERENCES}

1 Australian Bureau of Statistics. Apparent consumption of alcohol, Australia, 2007-08. Canberra: ABS, 2009. (ABS Cat. No. 4307.0.55.001.)

2 National Health and Medical Research Council. Australian guidelines to reduce health risks from drinking alcohol. Canberra: NHMRC, 2009.

3 Australian Institute of Health and Welfare. 2007 national drug strategy household survey: detailed findings. Canberra: AlHW, 2008. (AIHW Cat. No. PHE 107.)

4 Collins DJ, Lapsley HM. The costs of tobacco, alcohol and illicit drug abuse to Australian society in 2004/05. Canberra: Commonwealth of Australia, 2008.

5 Begg S, Vos T, Barker B, et al. The burden of disease and injury in Australia 2003. Canberra: Australian Institute of Health and Welfare, 2007. (AlHW Cat. No. PHE 82.)

6 Rose G, Daly S. The population mean predicts the number of deviant individuals. BMJ 1990; 301: 1031-1034.

7 Wagenaar AC, Salois MJ, Komro KA. Effects of beverage alcohol price and tax levels on drinking: a meta-analysis of 1003 estimates from 112 studies. Addiction 2009; 104: 179-190.

8 Australian Taxation Office. The alcohol industry - excise technical guidelines. Canberra: ATO, 2006. (Cat. No. NAT 14790-04.2006.)

9 European Commission. Excise duty tables: part I - alcoholic beverages. Brussels: European Commission, 2009. http://ec.europa.eu/ taxation_customs/index_en.htm\# (accessed Aug 2009).

10 Alcohol and Tobacco Tax and Trade Bureau. Taxes: tax and fee rate. Washington: US Department of the Treasury. http:// www.ttb.gov/tax_audit/atftaxes.shtml\#Beer (accessed Sep 2008).

11 Richardson J, Crowley S. Optimum alcohol taxation: balancing consumption and external costs. Health Econ 1994; 3: 73-87.

12 Clements KW, Selvanathan S. The economic determinants of alcohol consumption. Aust $J$ Agric Econ 1991; 35: 209-231.

13 Productivity Commission. Economic implications of an ageing Australia. Research report. Canberra: The Commission, 1995.

14 Chisholm D, Rehm J, Van Ommeren M, Monteiro M. Reducing the global burden of hazard- ous alcohol use: a comparative costeffectiveness analysis. J Stud Alcohol 2004; 65: 782-793.

15 Australian Institute of Health and Welfare. Health system expenditure on disease and injury in Australia, 2000-01. Canberra: AlHW, 2004. (AlHW Cat. No. HWE 26.)

16 Australian Bureau of Statistics. Consumer price index. Canberra: ABS, 2003. (ABS Cat. No. 6401.)

17 Barendregt JJ, Van Oortmarssen GJ, Van Hout BA, et al. Coping with multiple morbidity in a life table. Math Popul Stud 1998; 7: 29-49.

18 Cobiac LJ, Vos T, Doran C, Wallace A. Costeffectiveness of interventions to prevent alcohol-related disease and injury in Australia. Addiction 2010; 104: 1646-1655.

19 Corrao G, Rubbiati L, Bagnardi V, et al. Alcohol and coronary heart disease: a meta-analysis. Addiction 2000; 95: 1505-1523.

20 Ridolfo B, Stevenson C. The quantification of drug-caused mortality and morbidity in Australia, 1998. Canberra: Australian Institute of Health and Welfare, 2001. (AIHW Cat. No. PHE 29. Drug Statistics Series No. 7.)

21 English DR, Holman CD, Milne E, et al. The quantification of drug cause morbidity and mortality in Australia. Canberra: Commonwealth Department of Human Services and Health, 1995.

22 Stockwell T, Chikritzhs T, Bostrom A, et al. Alcohol-caused mortality in Australia and Canada: scenario analyses using different assumptions about cardiac benefit. J Stud Alcohol Drugs 2007; 68: 345-352.

23 Carter R, Vos T, Moodie M, et al. Priority setting in health: origins, description and application of the Australian Assessing Cost-Effectiveness initiative. Expert Rev Pharmacoecon Outcomes Res 2008; 8: 593-617.

24 Doran C, Shakeshaft A. What price for public health: using taxes to curb drinking in Australia. Lancet 2008; 372: 701-703.

25 Shakeshaft A, Doran CM, Byrnes J. The role of research in the failure of the alcopops excise in Australia: what have we learned? Med J Aust 2009; 191: 223-225.

(Received 30 Jun 2009, accepted 28 Sep 2009) 